\title{
História da política salarial docente de Mato Grosso do Sul
}

\author{
History of the machine salary policy of Mato Grosso do Sul
}

Daniel Stockmann ${ }^{1}$

\section{Resumo}

O texto lança um olhar sobre o processo de consolidação da carreira docente da rede estadual de ensino de Mato Grosso do Sul, a dinâmica de constituição dos dois primeiros estatutos da categoria (1981 e 1988) e as lutas do movimento sindical na aquisição de um piso salarial e condições adequadas de trabalho. Trata-se de uma análise pertinente para fins de compreensão da história do componente "valorização profissional", inscritas tanto nos planos plurianuais de educação (nacional e estadual) quanto nas discussões que permeiam a atual politica de remuneração docente. Trabalho e salário são duas faces de uma mesma moeda e constituem direitos fundamentais para a valorização simbólica e material da profissão. Foram realizadas análises bibliográfico-documentais e entrevistas como, técnicas de pesquisa, e o recorte histórico compreendeu de forma prioritária os anos a primeira década pós-divisão do então Estado de Mato Grosso. Conclui-se que a dimensão politica e econômica reforçam a necessidade da constante mobilidade associativa da classe trabalhadora para a garantia, manutenção e ampliação de seus direitos.

Palavras-chave: História. Salário docente. Trabalho docente.

\begin{abstract}
The text examines the process of consolidating the teaching career of the state education system in Mato Grosso do Sul, the dynamics of the constitution of the first two statutes of the category (1981 and 1988) and the struggles of the union movement in the acquisition of a floor appropriate working conditions. This is a pertinent analysis for the purpose of understanding the history of the "professional valuation" component, both in the multiannual educational plans (national and state) and in the discussions that permeate the current policy of teacher remuneration. Work and salary are two sides of the same coin and constitute fundamental rights for the symbolic and material valorization of the

\footnotetext{
${ }^{1}$ Natural de Mundo Novo - MS, Doutorando em Educação pela Universidade Federal de Mato Grosso do Sul - UFMS, Mestre em Sociologia pela Universidade Federal da Grande Dourados - UFGD, Especialista em Supervisão, Orientação e Inspeção Escolar pela Sociedade Educacional de Santa Catarina - SOCIESC. Graduado em Filosofia pela Universidade Católica Dom Bosco - UCDB e em Pedagogia pela Faculdade Paulista São José. Supervisor de Gestão Escolar - SED/MS. Possui experiência em Gestão da Educação, História, Políticas Públicas, Movimentos Sociais e Ação Coletiva. E-mail: danielstk@hotmail.com.
} 
profession. Bibliographical-documentary analyzes and interviews, such as research techniques, were carried out, and the historical clipping comprised as a priority the years the first decade after division of the then State of Mato Grosso. It is concluded that the political and economic dimension reinforce the need for the constant associative mobility of the working class to guarantee, maintain and expand their rights.

Keywords: History. Teaching salary. Teaching work.

\section{Introdução}

É importante conhecer o processo sociopolítico da divisão do Mato Grosso e as primeiras regulamentações sobre o trabalho dos servidores da educação básica no novo estado (Mato Grosso do Sul), suas peculiaridades e de que maneira foi concebido o tempo destinado ao planejamento do trabalho docente, especialmente, nos dois primeiros estatutos do magistério promulgados no estado. Ressalta-se que, apesar de ter a abordagem histórica como pano de fundo, o que se busca é analisar como foram consolidadas as políticas públicas de educação e quais suas consequências para a compreensão do tempo e remuneração como requisitos necessários à profissão docente.

Adotou-se a abordagem histórica tendo como técnicas a pesquisa bibliográfica, documental e entrevistas priorizando as fontes primárias. As entrevistas foram realizadas com pessoas que exerceram/exercem protagonismos nos momentos abordados, ocupando cargos estratégicos de direção na Federação dos Trabalhadores em Educação de Mato Grosso do Sul - FETEMS. Para fins de preservar o anonimato das fontes optou-se pela atribuição de nomes fictícios, entretanto, trata-se se de ex-presidentes e atuais dirigentes da referida instituição.

O estado de Mato Grosso do Sul foi criado através da Lei Complementar $n^{\circ}$ 31, de 11 de outubro de 1977, como medida de descentralizar a administração e facilitar os serviços prestados ao sul do então Mato Grosso. Todavia, a posse do primeiro governador se deu apenas em $1^{\circ}$ de janeiro de 
1979. Sobre esse episódio, o Jornal Correio do Estado, de 03 de janeiro de 1979, noticiava como matéria de capa:

Foi uma solenidade simples e que durou apenas 40 minutos, mas foi, também, muito emocionante e de alta significação para todos os mato-grossenses a de instalação do Estado de Mato Grosso do Sul, sob a presidência do presidente Ernesto Geisel, ao entardecer do dia $1^{\circ}$ de janeiro, anteontem, no Teatro Universitário Glauce Rocha. (CORREIO DO ESTADO, 1979).

É importante notar que, apesar do discurso oficial de que a divisão de Mato Grosso correspondia aos anseios populares, é discutivel o real interesse do movimento divisionista, pois havia elites agrárias sulistas que necessitavam maior projeção política, fato esse que demonstra o conflito entre o sul e o norte do mesmo estado. Desta maneira, não houve um plebiscito em que a população pudesse ser ouvida sobre o assunto. A mudança de poder político, que ocorreria como consequência da divisão, trazia, em si, o sonho de que a classe trabalhadora fosse contemplada como coadjuvante de uma nova história, havendo, assim maior valorização dos direitos sociais. Sobre isso havia a expectativa de que a divisão:

(...) iria resolver as diversas questões politicas relativas aos interesses imediatos das forças sociais que davam sustentação ao regime militar, como dos grupos latifundiários do sul de Mato Grosso (...) e a ampliação da base parlamentar da ditadura militar para dar sustentação à chamada abertura lenta e gradual implementada pelo governo Geisel (...). Não obstante, as reivindicações dos funcionários públicos não foram atendidas e eles continuavam com os seus salários congelados e defasados. (TOALDO, 2003, p. 72-73).

O contexto da criação do Mato Grosso do Sul está marcado pelas reações dos movimentos sociais contra o arrocho salarial, que permeou a década de 70 e as altas estratosféricas da inflação, que corroía o poder de compra dos trabalhadores, tornando rapidamente obsoletas quaisquer valorizações como reajustes salariais.

Ao falar do ato público, ocorrido na nova capital, no dia da divisão, bem como do clima de insegurança que era comum naquele regime político, José (Informação verbal) $)^{2}$ afirma que "nesse dia, era pra ser um dia de festa aqui

${ }^{2} \mathrm{O}$ nome é fictício para preservar a identidade da fonte. 
em Campo Grande. Houve o ajuntamento de 40, 50 pessoas na Praça Ary Coelho pra comemorar. Poxa! 40 pessoas? Por quê? Por que existia o medo. As pessoas não se manifestavam.” (JOSÉ, 2014).

Os primeiros momentos do novo estado foram marcados pela expressão de otimismo por parte das novas lideranças politicas que, por sua vez, buscavam legitimidade na inserção de novos atores sociais (entre eles o movimento docente) e, dentre os argumentos fortes de construção e reordenamento das novas instituições, encontra-se o ideário do "estado modelo".

Com a divisão do estado de Mato Grosso, no final da década de 1970, e a consequente reconfiguração do aparato legal oficial, houve a necessidade de organizar o ensino sob uma nova perspectiva jurídica. Essa necessidade passou a ser realidade a partir do Decreto-Lei $n^{\circ}$ 102, de 06 de junho de 1979. A partir deste marco legal, as atividades do magistério passam a ser caracterizadas como funções exercidas pelos Professores e Especialistas de Educação, sendo que estes últimos se subdividiam em Planejador escolar, Administrador escolar, Supervisor escolar, Inspetor escolar e Orientador Educacional (MATO GROSSO DO SUL, 1979). Este decreto, como se verá mais adiante, constitui-se em texto basilar para a consolidação do primeiro estatuto do magistério, publicado em 1981, no qual mantinham, no geral, as mesmas caracterizações estruturais e que já previa o tempo de trabalho (incluindo toda atividade docente) e o tempo de ensino (atividade docente exclusivamente com alunos). Ou seja, sob outra nomenclatura, já se apresentava um pequeno percentual de hora-atividade.

Sobre o referido Decreto-lei Moisés (Informação verbal) ${ }^{3}$, liderança sindical que participou da elaboração do mesmo e vivenciou sua aplicação diz:

(...) quando se divide Mato Grosso eu trabalhei em todas as equipes da área de educação, na elaboração de estatutos, na elaboração de leis, na elaboração de projetos de como se faziam as coisas aqui porque aqui não havia nada... Eu trabalhei com duas técnicas gaúchas... trabalhei na elaboração da lei 102,

\footnotetext{
${ }^{3}$ Moisés é um nome fictício para preservar a identidade da fonte.
} 
decreto lei de Harry Amorim Costa que na época era o estatuto do magistério mais avançado do país com a eleição direta para diretores, se bem que era triplice, com três candidatos, mas estabeleceu a denominação de professor, a carreira de professor, a carreira dos especialistas de educação, a comissão de valorização do magistério (...). (MOISÉS, 2015).

É bom notar que, apesar da previsão de contratação de duas formas (CLT e estatutário), presente no quadro provisório (o que predominava na prática), o primeiro Decreto-lei pressupunha, já neste contexto, o ingresso dos docentes e especialistas de educação através de concursos públicos de provas e títulos, sendo que, para os professores, os conteúdos da seleção seriam lingua portuguesa e fundamentos de educação, enquanto que para os especialistas, versariam também, além dos já elencados anteriormente: métodos, processos e técnicas aplicáveis à função. Esses concursos seriam anuais, de acordo com a necessidade, e teriam dois anos de validade (MATO GROSSO DO SUL, 1979).

Os trabalhadores que se destacassem em suas atividades recebiam certa condecoração de Mérito Educacional, sendo que havia a previsão de escolha dos "melhores", anualmente, e a premiação, segundo o artigo 57, seria no dia 15 de outubro, dia do professor. Observa-se que a meritocracia servia de estímulo à carreira educacional.

No quesito jornada de trabalho e tempo reservado para o planejamento de aulas, o texto jurídico afirma o seguinte:

Art. 58 - O membro do Magistério ficará sujeito a uma das seguintes jornadas de trabalho:

I - a minima, correspondendo a 12 horas semanais;

II - a básica, correspondendo a 22 horas semanais;

III - a especial, correspondendo a 40 horas semanais.

$\S 1^{\circ}$ - O Professor regente de classe que lecionar de $5^{\mathrm{a}}$ à $8^{\mathrm{a}}$ série do $1^{\circ}$ grau e no $2^{\circ}$ grau terá as seguintes horas dedicadas a atividades exercidas na Escola:

a) 2 horas para o Professor com jornada de trabalho de 12 horas;

b) 4 horas para o Professor com jornada de trabalho de 22 horas;

c) 8 horas para o Professor com jornada de trabalho de 40 horas.

$\S 2^{\circ}$ - O Professor que lecionar de $1^{\mathrm{a}}$ à $4^{\mathrm{a}}$ série do $1^{\circ}$ grau terá 2 horas semanais para atividades. (MATO GROSSO DO SUL, 1979, p. 13). 
Esta normatização legal insere-se em um momento importante da vida do estado e possui, como característica peculiar, a previsão de tempo específico para o planejamento de aulas. Neste contexto, não havia, no país, um entendimento, ou mesmo previsão jurídica nos sistemas de ensino, sobre o assunto. Veja que esta singularidade pode confirmar a ideia, exposta anteriormente, sobre a construção do estado modelo.

Verificam-se no artigo citado, anteriormente, algumas características interessantes: 1 - o tempo para o planejamento de aulas era exercido exclusivamente na unidade escolar, não havendo ainda neste contexto, a previsão do cumprimento em local de livre escolha; 2- há, proporcionalmente falando, maior tempo para planejamento para o docente com jornada de trabalho especial, se comparado com as demais jornadas; 3- os professores do ensino primário, independentemente da jornada de trabalho, só possuíam 2 horas para atividades, refletindo a hipótese de que sua função fosse concebida como de menor complexidade.

No quesito salário, é importante destacar que havia uma valorização maior para a jornada básica se for analisado em termos proporcionais e comparativos, pois, o parágrafo único do artigo 59 diz que "O salário correspondente às jornadas especial, básica e mínima terá, respectivamente, pesos 4, 2 e 1, observado o nivel e a classe." (MATO GROSSO DO SUL, 1979). É importante notar que a questão salarial sempre teve como pano de fundo a reflexão sobre as condições de trabalho e, neste aspecto, insere-se a problemática da hora-atividade.

Como fator de valorização salarial, o Decreto-lei estabelece incentivo financeiro para situações peculiares de trabalho, como lecionar em locais de dificil acesso, atuar em classes de alunos excepcionais, etc. Cabe aqui, destaque especial para o incentivo específico para os professores primários. $O$ parágrafo $3^{\circ}$, inciso VIII, do artigo 62 afirma que os professores das classes de alfabetização que possuíssem “curso específico" de alfabetização, receberiam o dobro do incentivo comum aos demais trabalhadores do ensino primário (MATO GROSSO DO SUL, 1979). A proliferação de incentivos financeiros como 
gratificações, por exemplo, criaram certa vulnerabilidade salarial, uma vez que mesmo o salário sendo irredutível, dentro da perspectiva legal, as gratificações podem ser suprimidas dependendo da vontade do governante. Da mesma forma, estas gratificações não incidem sobre os vencimentos para a aposentadoria.

Sobre essa diferença no incentivo que somaria ao salário dos professores primários, Joana (Informação verbal) ${ }^{4}$, fez a seguinte afirmação:

(...) já tivemos um período, que foi esse período anterior ao Zeca ${ }^{5}$, que a gente tinha assim: quem dava aula do primeiro ano tinha uma gratificação maior, a regência de classe era maior, e da educação especial também a regência de classe era maior, eu não lembro quanto, mas era em torno de uns vinte ou trinta por cento. A regência de classe era maior. (JOANA, 2014).

Outro incentivo trabalhista interessante era a Licença Prêmio. Ou seja, consistia em um afastamento remunerado do educador, sem prejuízo de seus vencimentos, pelo prazo de dois meses, por cada cinco anos de trabalhos continuos. Contudo, havia fatores condicionantes deste beneficio, conforme define o parágrafo único do artigo 63: "Não terá direito à licença-prêmio o membro do Magistério que contar, durante o quinquênio, mais de 3 meses de licença para tratamento de saúde, ou mais de 30 faltas, ainda que justificadas.” (MATO GROSSO DO SUL, 1979).

Conforme afirmado anteriormente, sobre a dimensão normativa de conceder a licença-prêmio somente àqueles que não se afastaram por motivo de saúde, ou outras razões devidamente justificadas durante determinado tempo levanta a hipótese de que haveria o interesse, por parte do estado, de manter o servidor na dinâmica laboral, mesmo em condições mais adversas ou extremas. Esse pressuposto seria uma estratégia de interesse, dentro de uma politica de eficiência educacional, em que os trabalhadores nem sempre seriam os maiores beneficiados.

\footnotetext{
${ }^{4} \mathrm{O}$ nome é fictício para preservar a identidade da fonte.

5 José Orcírio Miranda dos Santos (Zeca do PT) foi governador do estado de Mato Grosso do Sul pelo Partido dos Trabalhadores entre 1999 e 2006.
} 
De uma forma geral, pode-se concluir que, embora houvessem incentivos diversos vinculados a critérios meritocráticos da dinâmica trabalhista, a questão da ampliação da jornada para planejamento de aulas ainda não era pauta, tanto do movimento docente, quanto do governo. Permanecia a assimetria entre docentes que lecionavam no ensino primário e os demais educadores que diz respeito à carga horária destinada à preparação da atividade profissional.

No início do estado de Mato Grosso do Sul, uma vez que o regime político nacional era a ditadura, obviamente não havia eleições diretas para dirigentes escolares. Dessa maneira encontram-se, dentre os direitos assegurados, aos profissionais do magistério, o de "integrar a lista tríplice para as funções de Diretor e Diretor Adjunto", deixando subentendido que o processo de escolha seria de forma indireta, salvo exceções elencadas entre os artigos 68 e 71, como, por exemplo: em escolas com reduzido número de docentes, a escolha seria direta pelos próprios pares. As funções de diretor e diretor adjuntos eram ocupadas, preferencialmente, por especialistas de educação, sendo que o texto da lei diz dos “Administradores Escolares” (MATO GROSSO DO SUL, 1979). Veja que, se há, por um lado, o caráter técnico como postulado da função de direção de escolas, há, concomitantemente, por outro, a dimensão política, pois havia a nomeação.

A ocupação dos cargos de direção por critérios politicos afetaria, diretamente, a mobilização dos demais profissionais nas atividades de interesses corporativos ou de classe (como greves e paralisações), pois, o diretor era, em primeiro lugar, um agente de confiança do governo e apenas, de forma secundária (dada a formação de lista tríplice para a escolha), um representante da comunidade. Outro fator interessante a ser levantado é que se vivia em um contexto de reduzidos concursos públicos, sendo assim, a atribuição de aulas em caráter temporário serviria como moeda de troca na dinâmica política local. 


\section{A aprovação do $1^{\circ}$ estatuto do magistério estadual}

O primeiro estatuto, propriamente dito, do magistério sul-matogrossense se consolidou com a Lei Complementar $\mathrm{n}^{\circ} 04$ de 12 de janeiro de 1981, sendo considerado o primeiro plano de cargo e carreira docente. Esse plano tratou-se, na verdade, de um aprimoramento do Decreto-lei de 1979, não havendo grandes alterações no que compete ao regime trabalhista. Convém notar que já havia organização docente neste contexto, mas não se pode afirmar, com precisão, o impacto das reivindicações dessas entidades frente à edição do primeiro estatuto, uma vez que os principais meios de divulgação e manifestação de descontentamento eram através do Jornal Quadro Verde e por Cartas Abertas ao governador, quando este passava pelas cidades em eventos oficiais (BIASOTTO; TETILA, 1991).

As duas prioridades para o magistério, nos finais dos anos 70 e inícios dos 80, eram (...) "as péssimas condições materiais para o exercício da profissão e a deprimente condição salarial daquela época." (BIASOTTO; TETILA, 1991, p.60). Os problemas relacionados a tempo de trabalho nas unidades escolares versus tempo de planejamento não figuravam a centralidade das preocupações do movimento docente.

No início da década de 1980, havia a possibilidade de servidores públicos optarem pelo regime de trabalho alicerçado na CLT (Consolidação das Leis Trabalhistas). Essa peculiaridade fica expressa no artigo $3^{\circ}$ do estatuto do magistério, quando o mesmo se refere aos servidores do "Quadro Provisório" (MATO GROSSO DO SUL, 1981). Nota-se que, no Decreto-lei $\mathrm{n}^{\circ}$ 102/1979, no artigo 81, já dizia que "A Carteira de Trabalho e Previdência Social do Membro do Magistério será assinada pelo Agente Regional de Educação e todas as anotações serão processadas nas Agências Regionais de Educação." (MATO GROSSO DO SUL, 1979). Uma consideração pertinente deve ser feita aqui: esta particularidade predomina até a promulgação do primeiro estatuto do magistério (Lei $n^{\circ}$ 04/1981) em cujo artigo 32 fica assegurado que: 
Art. 32. O provimento dos cargos iniciais e finais das carreiras funcionais de professor e Especialista de Educação dependerá, sempre, de provas de habilitação, que consistirá em concurso público de provas e títulos (...). (MATO GROSSO DO SUL, 1981).

Veja que os professores do estado de Mato Grosso poderiam optar, com a divisão político-administrativa, em permanecerem no regime em que estavam, sejam estatutários ou celetistas, razão pela qual o artigo $3^{\circ}$, da Lei 04 de 1981 faz menção. Porém, a partir deste estatuto, os novos profissionais do quadro deveriam necessariamente passar para o quadro estatutário conforme a citação anteriormente do artigo 32 .

Quanto às condições de trabalho e a valorização profissional, a nova lei previa, em seu artigo $6^{\circ}$, parágrafo $1^{\circ}$, alínea c: "remuneração que assegure situação condigna nos planos econômico e social". Quanto a esse item, é interessante notar que não foi levado a sério, visivel na imprecisão da forma que fora redigido ficando fácil de burlar pelos governos que sucederam a promulgação do estatuto. O conceito de "situação condigna" de vida é genérico e de valor relativo. É importante lembrar que esta ideia de remuneração condigna dos professores volta à tona quando são discutidas as politicas de fundos como, por exemplo, no artigo $9^{\circ}$ da lei 9.424/1996, Lei do Fundo de Manutenção e Desenvolvimento do Ensino Fundamental e Valorização do Magistério - FUNDEF, e artigo 40, inciso I da lei 11.494/2007, Lei do Fundo de Manutenção e Desenvolvimento da Educação Básica - FUNDEB. (BRASIL, 1996; 2007).

Ainda segundo a lei complementar $n^{\circ} 04$, em seu artigo $6^{\circ}$, parágrafo $1^{\circ}$ e alínea $d$ encontra-se, postulado na lei, a "existência de condições ambientais de trabalho, pessoal de apoio qualificado, instalações e materiais didáticos adequados”. (MATO GROSSO DO SUL, 1981). Esse fator é de extrema relevância para a discussão trabalhista, pois, está diretamente relacionado com a qualidade de vida dos educadores ao longo do tempo. Com a jornada de 08 horas-atividade (para a carga máxima) a ser cumprido obrigatoriamente na escola esse item possui significado, pois em escolas grandes supõe-se que o número de professores, simultaneamente preparando aulas ou corrigindo avaliações, sob o mesmo espaço, era considerável afetando, dessa maneira, 
tanto a qualidade do ensino, quanto a saúde dos trabalhadores, em virtude das condições físico-estruturais em que se encontravam muitas escolas.

$\mathrm{Na}$ falta de profissionais efetivos, havia a possibilidade de lotação de professores sob as condições de suplência (substituição ou convocação). A substituição consistia na extensão da carga horária de professores já atuantes no quadro para suprir a lacuna de determinadas disciplinas, uma espécie de prorrogação de carga horária. O professor convocado é o profissional não vinculado ao quadro efetivo do estado, contratado temporariamente, todavia sem vinculo celetista. Isso demonstra a precariedade da situação funcional desses profissionais e que, perdura até os dias atuais. Este possuía uma remuneração inferior àquela paga para os demais profissionais com mesma habilitação. "Art. 44. O valor da hora-aula do professor convocado será igual a $80 \%$ do quociente da divisão do vencimento da classe A, do nível correspondente à sua habilitação (...).” (MATO GROSSO DO SUL, 1981).

Observa-se que a precarização da força de trabalho, já nesta época, se fazia sentir e de forma institucionalizada, legitimada pela lei. A distinção de tratamento entre convocados e efetivos é uma característica que prevalece até os dias atuais. Ou seja, enquanto uma proporção enorme do número de professores é constituída de convocados, para trabalhar de forma "temporária" (pois os governos não lançam concursos e quando o fazem as vagas são mínimas), os mesmos não possuem condições de crescer na carreira por não se enquadrarem no regime estatutário, tampouco nas condições previstas na CLT. Além destas condições, a situação da hora-atividade permaneceu intacta, sem alterações favoráveis à categoria por quase duas décadas.

A carga horária de trabalho dos integrantes do magistério estadual manteve as mesmas características no estatuto, se comparadas com as previstas pelo Decreto-lei 102 de 1979. As horas destinadas a planejamento também não sofreram nenhuma alteração. Foi mantida a mesma proporção já citadas anteriormente. Dessa forma, subentende-se que, independentemente, do regime que abrangia o trabalho docente, o que fora estipulado pelo Decreto- 
lei, em junho de 1979, no que tange ao tempo de ensino e ao tempo de trabalho, foi basilar e perpassou as demais leis sem alterações.

Quanto ao quesito remuneração, há um escalonamento de salários, de forma que cada classe e cada nivel recebam de acordo com determinado coeficiente. Vale lembrar que o piso salarial é a base de cálculos e representa a classe A nível I, de acordo com o artigo 64. Uma observação importante se faz pertinente, quando se olha para o parágrafo $2^{\circ}$ do referido artigo, pois há certa valorização através do estabelecimento de pesos, dependendo da carga horária do professor. Para 12 horas, o peso é 0,5; para 22 horas, peso 1,0 e para 40 horas semanais peso 1,5 (MATO GROSSO DO SUL, 1981). Assim, fica notório que no final, recebe maior valorização aquele profissional com carga horária básica de 22 horas semanais. Ressalta-se, todavia, que isto poderia significar melhores condições de remuneração e trabalho, se o Estado valorizasse e estimulasse a contratação básica (22 horas), mas seria o contrário se estimulasse a contratação de jornada mínima (12 horas) ou especial (44 horas).

Encontra-se, entre os direitos dos educadores, o de serem designados para as funções de diretores e diretores adjuntos, porem há uma alteração no processo de escolha, tal como havia sido regulamentado pela legislação anterior. Em outras palavras, a partir desta lei complementar ( $n^{\circ} 04$ de 1981), os referidos cargos passam a ser designados pelo governador, conforme prega o parágrafo único, do artigo 75. Passa a ser critério para exercê-los, (segundo o artigo 73), ser licenciado em pedagogia com habilitação em administração escolar, bem como possuir no mínimo três anos de experiência de ensino (MATO GROSSO DO SUL, 1981). Neste ponto, há um retrocesso, se comparado com o processo de escolha previsto até então, pois, mesmo com as limitações existentes com a lista tríplice, havia certo grau de consulta à comunidade escolar na escolha.

Esta alteração expressa que não há uma linearidade nas conquistas dos direitos trabalhistas, podendo haver retrações. Isso justifica a ideia de que os 
trabalhadores em educação, além de lutar por melhorias, precisam garantir, através das entidades sindicais, que não percam o que já conquistaram.

A luta sindical sul-mato-grossense foi bem representada pela fundação da FEPROSUL - Federação dos Professores de Mato Grosso do Sul - a 03 de março de 1979, oriunda do esforço das associações municipais de professores que, dentre outras cabe enfoque especial à ACP - Associação Campograndense de Professores - e à ADP - Associação Douradense de Professores, ambas já existentes e com certa militância por uma política trabalhista e salarial mais justa. Esse dinamismo da luta pela categoria resultou na primeira greve geral da categoria em 10 de novembro de 1981 onde se reivindicava reajuste salarial de $108 \%$ e pagamento de salários atrasados (BIASOTTO; TETILA, 1991).

A ACP e a ADP eram associações com uma história de militância construída bem antes da organização da FEPROSUL. As lideranças destas instituições acumulavam certa experiência no movimento reivindicativo e isso foi importante quando surge a ideia da criação de uma federação.

O modelo federativo de organização docente, que é uma singularidade que se manteve no sindicalismo sul-mato-grossense se comparado com outros modelos pelo país, teve sua relevância na tomada de decisões sobre a política de negociações trabalhistas. A primeira greve citada anteriormente, por exemplo, foi produto da iniciativa da ADP, uma das associações de base e não da federação como um todo. Sobre esse fenômeno Biasotto\&Tetila (1991) afirmam que:

\footnotetext{
O fato de ter sido a ADP a iniciadora da greve e não a FEPROSUL, enseja que se abra um parêntesis para se fazer mais uma vez a apologia do sistema federativo de organização dos professores matogrossulenses. Quando a Federação emperra, uma outra, ou várias associações municipais levam a reboque a própria federação. Quando uma ou outra ou várias associações municipais emperram, a federação as leva a reboque. Isso faz com que o movimento reivindicatório do magistério de Mato Grosso do Sul seja mais dinâmico que em outros estados brasileiros, onde os professores estão organizados à base de associações. (BIASOTTO; TETILA, 1991, p. 116).
} 
No estado recém-criado desenvolveu-se a utopia de construir o "novo" e "diferente", como forma de distinguir as novas instituições das praticas politicas tradicionais, possivelmente, como forma de negação do regime ditatorial que já demonstrava certo desgaste, naquele momento histórico. Desta maneira, a medida que o ideário de "estado modelo" foi se concretizando, a organização de classe docente foi se construindo como uma estrutura que não aglutinasse as associações de base já existentes fundindoas, mas que se criasse uma federação onde cada associação mantivesse sua identidade inalterada e agregasse, espontaneamente, seu apoio à entidade estadual o que garantiria maior heterogeneidade ao movimento. Essa análise é importante para ilustrar que, em outros estados, as organizações sindicais geralmente são concebidas de formas verticalizadas e unificadas por esfera de governo. Há sindicatos com abrangências estaduais, por exemplo, enquanto outros representam apenas os servidores das redes municipais.

Voltando à abordagem sociopolítica, deve-se ponderar que a instabilidade inflacionária (que já sinalizava a crise do modelo de política econômica centrada no Estado), aliada à desvalorização por parte do governo para com os professores, foram os maiores problemas enfrentados pela categoria na vigência do primeiro estatuto profissional. Em reunião entre presidentes das associações de professores e o então presidente da FEPROSUL (Federação dos Professores de Mato Grosso do Sul) Antônio Carlos Biffi, em 1986, dentre outros assuntos, consta-se o seguinte:

\footnotetext{
O presidente declarou que a FEPROSUL fez ampla discussão sobre o piso salarial com a diretoria, consultou Brasilia sobre a questão e chegou-se a conclusões de que devemos estar alertas e brigarmos usando todos os recursos para que se mantenha o nosso piso salarial e que após sejam abertas as negociações para o terceiro piso salarial, partindo até para a greve se necessário. (FEPROSUL, 1986, p. 93). ${ }^{6}$
}

A atuação da FEPROSUL foi decisiva nos embates travados entre categoria e governo na década de 1980. Prova disso é a resposta do então governador Pedro Pedrossian, ao suspender o desconto em folha da arrecadação das associações de base e a criação em 1981 da APMS-

\footnotetext{
${ }^{6}$ Este documento atualmente faz parte do arquivo histórico da FETEMS. Interfaces da Educ., Paranaíba, v.9, n.27, p. 81-103, 2018
} 
Associação de Professores de Mato Grosso do Sul, como forma de dividir e fragilizar a classe docente. Criticando essa postura de Pedrossian, ao criar a APMS para contrapor à entidade dos professores, Biasotto\&Tetila (1991, p. 125) afirmam que “(...) ao contrario da Federação dos Professores do Mato Grosso do Sul - FEPROSUL - nasceu sem a participação nas bases. Parida nas salas palacianas, surgiu para defender os interesses do governo."(BIASOTTO; TETILA, 1991, p. 125). Embora tenha sido uma medida politica de enfrentamento aos trabalhadores, a APMS foi extinta tão logo acabou a gestão de Pedrossian.

Enfim, pode se concluir que a primeira lei complementar, que regulamenta o ensino básico em Mato Grosso do Sul representou avanços e retrocessos na perspectiva das relações de trabalho dos servidores. Não pode ser desconsiderado o processo histórico e político, no qual o país estava inserido: fortes apelos pela redemocratização por parte da sociedade civil, grandes mobilizações dos movimentos sociais para recomposição dos diretos civis e trabalhistas perdidos com o duro arrocho salarial assistido pelos trabalhadores na década anterior, etc. Os embates que se travariam no estado estavam conectados com o contexto nacional.

O processo de abertura política, iniciado no final dos anos 1970, aliado ao ideário de se fazer do mais novo estado da federação um exemplo, tanto do ponto de vista econômico, quanto da organização administrativa, são alguns fatores que esclarecem porque, mesmo não havendo tanta pressão da categoria docente, num primeiro momento, houveram alguns avanços relacionados ao reconhecimento sócioprofissional.

\section{A Lei Complementar $n^{\circ} 35$, de 12 de janeiro de 1988}

Como visto até aqui o primeiro estatuto do magistério aprovado em 1981 na verdade, reafirmou o Decreto-lei outorgado em junho de 1979, sem grandes alterações. Isso não significa que aquele estatuto não representasse vantagem para os trabalhadores, uma vez que, como se verá a partir de agora, muitos dos princípios normativos estabelecidos naquela lei continuaram presentes no segundo estatuto (Lei 035/1988), como é o caso, por exemplo, da permanência 
na carreira da retribuição pelos títulos de especialistas, mestres e doutores. Entretanto, após o primeiro estatuto, houve, ora aprimorados diálogos, ora acalentados conflitos, entre movimento sindical e o governo, havendo greves e manifestações, em muitas ocasiões. Dessa maneira, não se pode afirmar que há similitudes entre ambos os estatutos (04/1981 e 035/1988), neste quesito.

Após uma longa trajetória de diálogos e conflitos envolvendo a FEPROSUL, as associações de base e o governo, é aprovado, no dia 12 de janeiro de 1988, o novo estatuto do magistério público, alterando e revogando a lei complementar $n^{\circ} 04$ de 1981. A aprovação desta nova lei está inserida em um contexto de profundas reflexões, em nivel nacional, sobre a consolidação legal da democracia e do sistema político através do processo constituinte, cuja culminância se deu na promulgação da Carta Magna, no mesmo ano. Convém frisar que a promulgação da Constituição Federal ocorreu em 05 de outubro de 1988, portanto, após a lei do magistério, razão pela qual este teve que se adequar àquela.

Nos anos que intermediaram a Lei Complementar no 04 de 1981 e este novo estatuto, pode-se afirmar que o movimento reivindicatório cresceu muito em termos organizativos. Percebe-se que os educadores, através da FEPROSUL, e por intermédio de suas reuniões de presidentes, debatiam a possibilidade de participar, assiduamente, da consolidação do processo democrático que se construía. Isso fica expresso através de discussões a respeito da indicação de membros a serem constituintes (participando eventualmente da construção da nova constituição federal) e mesmo para as eleições estaduais, sendo que um dos nomes influentes, a representar a classe trabalhista docente, era a do professor Antônio Carlos Biffi (Cf. Ata de 13 de março de 1986), que, posteriormente, tornou se deputado federal eleito.

A aprovação da lei $n^{\circ}$ 35/1988 está inserida em um contexto em que se debate, intensamente, não só a educação, mas, sobretudo, os direitos sociais e cidadania, tendências estas confirmadas, posteriormente, no texto constitucional. Apesar do desgaste causado por diversas greves na década de 1980, o papel das associações de professores foi fundamental para a 
ampliação de direitos trabalhistas. Houve momentos de profunda defasagem salarial, por conta dos sucessivos aumentos da inflação, e estas reposições de perdas, aliadas à reivindicação de um piso de pelo menos 03 salários mínimos foram os principais motivos das mobilizações docentes.

À medida que a FEPROSUL se mobilizava e conquistava notoriedade na sociedade sul-mato-grossense, fortalecia a sua identidade institucional, não somente como entidade de representação da categoria docente, mas como porta voz da justiça social, conforme afirma José (Informação verbal). Houve um momento em que o governo pressionou o Banco Bamerindus (atual HSBC) a cortar o desconto automático da contribuição dos filiados, como tentativa de coibir o fortalecimento da federação sindical, por exemplo. Após longa e intensa negociação com a gerência do banco em Curitiba e, já no ultimo momento de sua gestão, o governo reverteu a situação da consignação em folha (JOSÉ, 2014).

No plano da valorização salarial, há certo avanço, especialmente, na alteração da maneira que era remunerado o professor convocado. Ou seja, o mesmo passa a ter equiparação salarial à classe A, nível inicial da carreira, conforme se lê no artigo 41: “Art. 41. O valor da hora-aula do Professor convocado será igual à do vencimento da classe A, no nivel correspondente a sua habilitação”. (MATO GROSSO DO SUL, 1988). Dessa maneira, tanto professores efetivos, quanto temporários, tiveram equiparação salarial, apesar, obviamente, de a condição do contratado continuar precária, do ponto de vista da possibilidade de ascensão funcional, retribuição por títulos, tempo de serviço, regime previdenciário etc.

Os profissionais da educação passam a contar com mais incentivo que no estatuto anterior quanto à capacitação e atualização funcional. Este estatuto prevê o incentivo, através de bolsa de estudos, para aqueles que almejarem participar de cursos voltados para suas áreas de atuação. O único critério condicionante para tal benefício é, segundo os artigos de 57 a 59, ser efetivo e ter computado no mínimo quatro anos de serviço. Aqueles que se 
afastarem para formação devem cumprir serviço no estado de no mínimo o dobro do tempo do afastamento (MATO GROSSO DO SUL, 1988).

Outro aspecto relevante que foi mantido, desde a primeira regulamentação das relações de trabalho dos professores, são os estudos adicionais e o curso de doutorado, como válidos para fins de valorização e de acréscimo, na remuneração dos profissionais da educação. Este aspecto é interessante, pois, como se verá oportunamente neste trabalho, apesar de um longo período de lutas, no próximo estatuto (aprovado em 2000), os "estudos adicionais" e o doutorado foram retirados da carreira. Salienta-se que apesar da previsão do titulo de doutor como forma de valorização na carreira, o mesmo foi, por muito tempo, simbólico, dado à inexistência de profissionais com esta pós-graduação no quadro. Esta reflexão é pertinente por que a propositura da retirada deste título da carreira partiu da própria Federação dos Trabalhadores em Educação de Mato Grosso do Sul - FETEMS7.

Com relação à carga horária e o tempo destinado ao planejamento, não houve grandes mudanças se analisado comparativamente com as leis anteriores. Destaca-se, apenas, a definição explicativa no texto legal do objetivo da hora-atividade, como sendo um tempo de planejamento do trabalho docente, reunião com pais, alunos e correção de provas. Outro aspecto que altera o estatuto antigo é a limitação máxima de 4 horas-aulas consecutivas ou 8 horas-aulas intercaladas para os professores, sendo que a duração de cada aula no diurno seria de 50 minutos e no noturno de 45 minutos (MATO GROSSO DO SUL, 1988).

A tabela a seguir ilustra algumas das mudanças advindas da nova lei objeto desta discussão:

\footnotetext{
7 A Federação dos Professores de Mato Grosso do Sul - FEPROSUL deu lugar a esta entidade nos anos 1990 no Congresso Estadual realizado em Amambai. Essa mudança de nomenclatura simbolizou a expansão do conceito de profissionais de educação à todos os servidores que atuam nas escolas, além dos professores.
} 


\section{Lei 04/ 1981}

$\S 1^{\circ} \mathrm{O}$ professor de $5^{\mathrm{a}}$ a $8^{\mathrm{a}}$ série de $1^{\mathrm{o}}$ grau ou de $2^{\circ}$ grau terá as seguintes horas dedicadas às atividades exercidas na escola:

I - 2 horas para o professor com 12 horas;

II - 4 horas para o professor com 22 horas;

III -8 horas para o professor com 40 horas;

$\S 2^{\circ} \mathrm{O}$ professor que lecionar de $1^{\mathrm{a}}$ à $4^{\mathrm{a}}$ serie do $1^{\circ}$ grau terá duas horas semanais para atividades.

\section{Lei $035 / 1988$}

$\S 1^{\circ} \mathrm{O}$ professor de $5^{\mathrm{a}}$ a $8^{\mathrm{a}}$ série de $1^{\circ}$ grau ou de $2^{\circ}$ grau terá as seguintes horas dedicadas às atividades na escola:

I - 2 (duas) horas-aulas para o professor com 12 (doze) horas-aulas; II - 4(quatro) horas-aulas para o professor com 22 horas-aulas;

III - 8(oito) horas-aula para o professor com 40 horas-aulas;

$\S 2^{\circ}$ A hora-atividade é um tempo remunerado, de duração igual ao da hora-aula, de que disporá o professor, prioritariamente, para participar de reuniões pedagógicas e, ainda, para preparação de aulas, correção de provas, pesquisas e atendimento a pais e alunos.

$\S 3^{\circ} \mathrm{O}$ professor não poderá ministrar, por dia, mais de 04 (quatro) horasaulas consecutivas, nem mais de 08 (oito) intercaladas.

Art. 67. A hora-aula, ministrada pelo professor e cumprida pelo especialista de educação, terá duração mínima de 50 (cinquenta) minutos no período diurno e 45 (quarenta e cinco) minutos no período noturno.

Fonte: tabela elaborada pelo autor com dados das referidas leis complementares.

Um detalhe interessante do estatuto de 1988 é que, pela primeira vez, se estabelece, legalmente, o conceito de piso salarial de acordo com determinada carga horária, que, neste caso, a referência é 22 horas-aulas. "Art. 69. Piso Salarial: é o fixo para a Classe A da respectiva categoria funcional, ao nível de habilitação mínima, correspondente à carga horária de 22 horas-aulas semanais de trabalho.” (MATO GROSSO DO SUL, 1988). Na legislação anterior, havia a referência ao piso salarial, porém sem indicar a que jornada de trabalho seria. É a partir desse novo pressuposto que se dará toda a discussão posterior sobre o piso salarial no estado.

O adicional por tempo de serviço é um item importante incluído na Lei Complementar $n^{\circ} 35 / 88$, pois estabelece, independentemente de graduação ou merecimento, uma retribuição de acordo com a antiguidade no serviço 
público. Segundo o artigo 75 da referida lei, a gratificação leva em consideração cada quinquênio de serviço prestado, sendo que no primeiro será de $10 \%$ e nos demais 5\% até completar um total de 40\% (MATO GROSSO DO SUL, 1988).

As funções de diretor, diretor-adjunto e agentes de educação continuaram na presente lei como de livre nomeação do governador, não havendo, ainda neste contexto, a hipótese da gestão democrática nos estabelecimentos de ensino. Observa-se que, mesmo após todo o movimento pró-democratização da sociedade como um todo, ao longo da década de 1980, não houve avanço significativo que refletisse no sistema estadual de ensino de Mato Grosso do Sul.

Apesar da previsão legal de tempo destinado ao planejamento de aulas, desde o processo divisionista do estado, não se pode falar que houve grande novidade com relação à consolidação da hora-atividade, como momento que dessem condições significativas para preparar o trabalho a ser executado, posteriormente, com os alunos. Na proporção da jornada de trabalho, as duas, quatro ou oito horas-aulas de planejamento, correspondente às jornadas mínima, básica e especial, representavam 16,5\%, 18\% e 20\% da carga de trabalho, respectivamente, a serem cumpridas, exclusivamente, na escola.

Sendo assim, em todos os casos, é possivel concluir que os professores levariam trabalhos para serem executados em suas casas, pois o trabalho nesta acepção não se resume apenas ao planejamento de aulas, mas como a própria redação do estatuto do magistério de 1988 define como sendo o de “(...) participar de reuniões pedagógicas (...) correção de provas, pesquisa e atendimento a pais e alunos.” (MATO GROSSO DO SUL, 1988).

Enfim, pode-se afirmar que a evolução do trabalho docente, enquanto profissionalização é resultado dos conflitos e antagonismos vivenciados pela sociedade como um todo. De um ensino individualizado e descontínuo, passase a uma coletivização da atividade, em que havia a economia de recursos e de tempo. A reprodução da força de trabalho, como necessidade da expansão produtiva, e a educação, como direito social expressada e abrangida com o Interfaces da Educ., Paranaíba, v.9, n.27, p. 81-103, 2018 
ideal de civilização e progresso, trazem, à tona, a demanda por maiores investimentos que propiciasse uma política educacional compativel com as transformações da sociedade brasileira. É dentro desta perspectiva que as diversas constituições federais e as várias reformas educacionais condensaram, em maior ou menor proporção, os anseios da sociedade civil, por um lado, e as necessidades do mercado, por outro. Exemplo disso é a coexistência do ensino público e gratuito com a liberdade de exploração do ensino pela iniciativa privada ao longo de todo esse processo.

\section{Considerações finais}

Observaram-se neste texto as dificuldades que a classe trabalhadora e em especial a categoria docente enfrentou para a tentativa de conquista de espaço enquanto servidores públicos, como sujeitos históricos, dotados de autonomia e relevância para a sociedade. Esse processo é resultado da histórica e gradativa ruptura com a visão mística da atividade de ensino, e a transição para uma concepção de que, sem professores preparados enquanto atores sociais capazes de dar respostas às necessidades sociais não há desenvolvimento tanto do ponto de vista cultural quando econômico e produtivo.

O que importa, e acredita-se que com este artigo foi possivel, é compreender os avanços nas condições de trabalho, como resultados dos embates de classe por um lado, e das demandas sociais de outro. A consolidação da educação como direito social está integrada à expansão da sociedade industrial. Sendo assim a qualidade do serviço a ser prestado pelos professores ao seu público depende concomitantemente de condições de trabalho favoráveis, de tempo para planejamento e neste sentido se faz importante falar em hora-atividade.

A legislação citada durante este texto permite refletir, sobre esse processo como necessidade, social e cultural, devendo ser pensada para além de políticas de governos, mas como política de Estado. Os preceitos constitucionais de 1988 que estabelecem a educação como livre, gratuita, 
sendo um dever da família e do Estado associadas à legalização do sindicalismo do setor público coroam, em certo sentido a evolução da profissionalização docente.

Este breve histórico da educação sul-mato-grossense reflete as condições sociais e econômicas que permearam o final do século XX, e de certa maneira convergiram para a estruturação do neoliberalismo nos anos 1990, com duras consequências para as politicas públicas em educação. É importante pensar as reformas do Estado e do ensino como dois acontecimentos inter-relacionados à reestruturação do sistema produtivo acontecido nesta década.

Analisar os primeiros estatutos da categoria docente faz pensar de que forma as condições foram adequando-se às demandas do sistema de ensino na rede estadual de Mato Grosso do Sul. No inicio dos anos 2000 foi aprovado o $3^{\circ}$ estatuto sob a Lei Complementar $n^{\circ} 087$ de 31 de janeiro de 2000, representando um salto importante no enquadramento de todos os servidores administrativos como profissionais da educação. Dadas às relações politicas implicadas e o novo contexto histórico este seria assunto para novos estudos.

\section{Referências}

BIASOTTO, Wilson Valentim; TETILA, José Laerte. O movimento reivindicatório do magistério público estadual de Mato Grosso do Sul: 19781988. Campo Grande: UFMS, 1991.

BRASIL. Decreto-lei $n^{\circ} 5452$, de $1^{\circ}$ de maio de 1943. Aprova a Consolidação das Leis do Trabalho.

Lei $n^{\circ} 11.494$, de 20 de junho de 2007. Regulamenta o Fundo de Manutenção e Desenvolvimento da Educação Básica e de Valorização dos Profissionais da Educação - FUNDEB, de que trata o art. 60 do Ato das Disposições Constitucionais Transitórias; altera a Lei 10.195, de 14 de fevereiro de 2001; revoga dispositivos das Leis $n^{\circ} 9.424$, de 24 de dezembro de 1996, 10.880, de 9 de junho de 2004, e 10.845, de 5 de março de 2004; e dá outras providências. 
Lei $n^{\circ}$ 9.424, de 24 de dezembro de 1996. Dispõe sobre o Fundo de Manutenção e Desenvolvimento do Ensino Fundamental e de Valorização do Magistério, na forma prevista no art. $60, \S 7^{\circ}$, do Ato das Disposições Constitucionais Transitórias, e dá outras providências.

FEDERAÇÃO DOS TRABALHADORES DE EDUCAÇÃO DE MATO GROSSO DO SUL. Reunião Ordinária. Ata de 13/05/1986, p. 93.

JOANA. Depoimento concedido em 04 de outubro de 2014 na sede da FETEMS. Entrevistador: Daniel Stockmann.

JORNAL CORREIO DO ESTADO. Publicação de 03 de janeiro de 1979, p. 05. Campo Grande, Mato Grosso do Sul.

JOSÉ. Depoimento concedido na sua residência em 13 de outubro de 2014. Entrevistador: Daniel Stockmann.

MATO GROSSO DO SUL. Decreto-lei $n^{\circ} 102$, de 06 de junho de 1979. Dispõe sobre o Plano de Carreira do Magistério e dá outras providencias.

Lei Complementar $n^{\circ}$ 087, de 31 de janeiro de 2000. Dispõe sobre o Estatuto dos Profissionais da Educação Básica do Estado de Mato Grosso do Sul e dá outras providencias.

. Lei Complementar $n^{\circ}$ 35, de 12 de janeiro de 1988. Dispõe sobre o Estatuto do Magistério Estadual de Mato Grosso do Sul e dá outras providencias.

Lei Complementar $n^{\circ} 04$, de 12 de janeiro de 1981. Dispõe sobre o Estatuto do Magistério Estadual de Mato Grosso do Sul e dá outras providencias.

MOISÉS. Entrevista concedida em sua residência no dia 13 de janeiro de 2015. Entrevistador: Daniel Stockmann.

TOALDO, Ciro José. O Novo Sindicalismo e a mobilização dos professores da rede publica estadual sul-mato-grossense: Avanços e Ruptura (1979/1992). Dourados: Universidade Federal de Mato Grosso do Sul, 2003. Dissertação (mestrado) apresentada ao Programa de Mestrado em História da UFMS, 188 p. 